\title{
Depletion of spotted and spinner dolphins in the eastern tropical Pacific: modeling hypotheses for their lack of recovery
}

\author{
Paul R. Wade ${ }^{1, *}$, George M. Watters ${ }^{2}$, Tim Gerrodette ${ }^{2}$, Stephen B. Reilly ${ }^{2}$ \\ ${ }^{1}$ NOAA Fisheries, Alaska Fisheries Science Center, National Marine Mammal Laboratory, 7600 Sand Point Way N.E., \\ Building 4, Seattle, Washington 98115, USA \\ ${ }^{2}$ NOAA Fisheries, Southwest Fisheries Science Center, Protected Resources Division, 8604 La Jolla Shores Drive, La Jolla, \\ California 92037, USA
}

\begin{abstract}
We assess the status of 2 dolphin stocks affected by purse-seine fishing in the eastern topical Pacific and evaluate hypotheses for their lack of recovery. We use Bayesian methods and fit generalized models of logistic population growth to abundance estimates for northeastern offshore spotted dolphins Stenella attenuata attenuata and eastern spinner dolphins Stenella longirostris orientalis. In 2002, using the definition of depletion stipulated in the USA Marine Mammal Protection Act, northeastern offshore spotted dolphins were almost certainly 'depleted'. There is, however, uncertainty in the degree to which the stock was depleted. Eastern spinner dolphins were most likely depleted in 2002, but there is a small probability that this was not the case. Uncertainty in the degree to which both stocks were depleted stems from uncertainties in maximum net productivity levels and carrying capacities. Based on abundance data from 1979 to 2000, both stocks were estimated to have had maximum growth rates of $<3 \% \mathrm{yr}^{-1}$ with $>77 \%$ probability, lower than the accepted minimum default value for dolphin populations with reproductive parameters (e.g. calving intervals) like those considered here (Reilly \& Barlow 1986, Fish Bull 84:527-533; Wade 1998, Mar Mamm Sci $14: 1-37)$. We fit models that are intended to be indicative of hypotheses that explain why neither dolphin stock has recovered. Our data and prior information provide equal posterior support to hypotheses which attribute the lack of recovery to the fishery and changes in the ecosystem. We conclude that (1) the purse-seine fishery can impact dolphin stocks beyond the impacts of observed fishery mortality, (2) there is uncertainty about the degrees to which such cryptic impacts have population-level consequences, and (3) the existing dolphin-safe labeling standard is, from a conservation perspective, robust to this uncertainty.
\end{abstract}

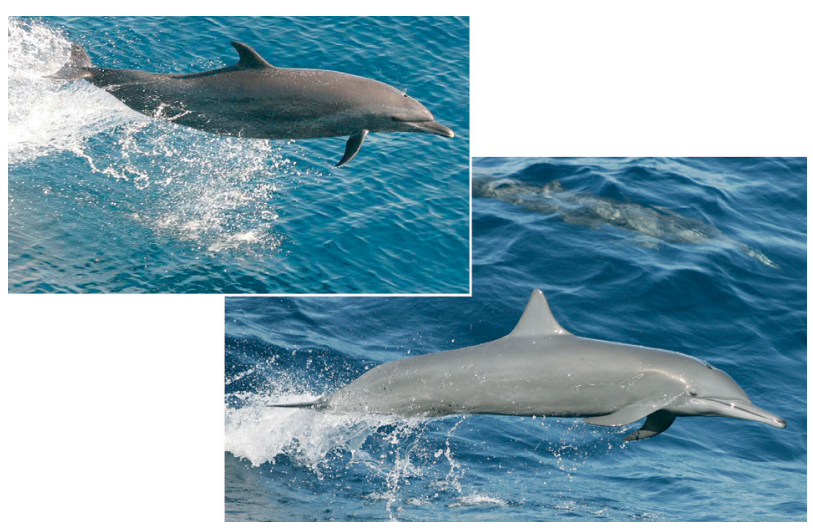

Populations of northeastern offshore spotted (top) and eastern spinner (bottom) dolphins in the eastern tropical Pacific have not recovered as expected.

Photos: Robert Pitman (NOAA)

KEY WORDS: Tuna-dolphin issue - Dolphin-safe labeling · Stenella attenuata $\cdot$ S. longirostris $\cdot$ Status assessment · Fishery $\cdot$ Ecosystem effects $\cdot$ Bycatch

Resale or republication not permitted without written consent of the publisher

\section{INTRODUCTION}

Dolphins of several species are incidentally killed during tuna purse-seine fishing in the eastern tropical Pacific Ocean (ETP). Fishermen use the dolphins to locate schools of tuna, and often purposely chase and encircle the dolphins in their nets to maximize their catch of tuna (Perrin 1969, Joseph \& Greenough 1979). The main species killed are spotted dolphins Stenella attenuata, spinner dolphins S. longirostris, and com- 
mon dolphins Delphinus delphis. Over the period 1960 to 1972 , more than 4 million dolphins were killed by purse-seine vessels fishing for yellowfin tuna Thunnus albacares in the ETP (Wade 1995). At least 3 dolphin stocks-northeastern offshore spotted dolphins $S$. attenuata attenuata, coastal spotted dolphins $S$. attenuata graffmani, and eastern spinner dolphins $S$. longirostris orientalis-declined because of the mortality incurred during the 1960s and early 1970s, and were consequently designated 'depleted' under the USA Marine Mammal Protection Act (MMPA) (Smith 1983, Wade 1993, 1994). Gerrodette \& Forcada (2005) provide a recent assessment of the trends of dolphin stocks in the ETP and conclude that, despite reductions in fishing mortality which span 2 orders of magnitude, neither the stock of northeastern offshore spotted dolphins nor that of eastern spinner dolphins had increased in abundance by the year 2000. Thus, neither stock was considered to be recovering.

The results presented by Gerrodette \& Forcada (2005) set the stage for further retrospective study in 2 ways. First, Gerrodette \& Forcada (2005) provide 12 estimates of abundance, covering the period 1979 to 2000 , for both northeastern offshore spotted and eastern spinner dolphins. These abundance estimates can be used in combination with a population-dynamics model and data on observed kills to (1) re-assess whether the 2 stocks were depleted in 2002 relative to historical levels of abundance and (2) estimate each stock's maximum rate of population growth. Second, Gerrodette \& Forcada (2005) initiate a discussion about hypotheses that can explain the apparent lack of recovery by dolphin stocks in the ETP. These hypotheses fall into 3 general categories: fishery effects, ecosystem effects, and effects from complex population dynamics. Evaluating the competition among these alternatives in a common modelbased framework may be useful because some effects (e.g. fishery effects) have an obvious bearing on conservation and management issues while others (e.g. ecosystem effects) may not. In particular, one conservation issue that has received recent attention is whether fishing for tuna by chasing and encircling dolphin schools is harmless for the dolphin populations if no dolphin deaths are observed during such activities. Other lines of research have shown that there could be considerable 'cryptic' (unseen) deaths from chase and encirclement (e.g. Archer et al. 2001, 2004), which suggests that the apparent lack of recovery noted by Gerrodette \& Forcada (2005) is from this source.

We have 2 objectives in this paper. First, we assess the status of the northeastern offshore spotted and eastern spinner dolphin stocks as of 2002. Second, we consider whether the lack of recovery by these stocks can be attributed to fishery effects or ecosystems effects, using a Bayesian model comparison method.

\section{MATERIALS AND METHODS}

Data. Estimates of bycatch and abundance, covering the period 1959 to 2002 (Table 1), provide the empirical bases for our work. We obtained stock-specific estimates of the numbers of dolphins killed by the purseseine fishery from 3 sources. We used bycatch kill estimates from (1) Wade (1995) for the period 1959 to 1972, (2) J. Joseph (unpubl. data: letter from J. Joseph to M. Tillman dated 6 September 1994) for the period 1973 to 1984, and (3) IATTC $(2002 a, b, 2004)$ for the period 1985 to 2002. We obtained stock-specific estimates of abundance from Gerrodette \& Forcada (2005). These abundance estimates were developed from covariate line-transect models (Marques \& Buckland 2003, Forcada et al. 2004, Gerrodette \& Forcada 2005) that were fitted to sighting data collected during research surveys in the ETP.

Models. We used generalized models of logistic population growth (Pella \& Tomlinson 1969) to characterize the dynamics of both northeastern offshore spotted and eastern spinner dolphins. In discrete time, the abundance of dolphins from a single stock (we modeled each stock separately) in year $t\left(N_{t}\right)$ is determined from the abundance in the previous year, the density-dependent net recruitment of new individuals to the stock (from births and natural mortality), and the number of deaths caused by fishing $\left(C_{t}\right)$ :

$$
N_{t+1}=N_{t}+r_{i} N_{t}\left[1-\left(\frac{N_{t}}{K_{i}}\right)^{Z}\right]-C_{t}
$$

where $K_{i}$ is the carrying capacity during period $i_{\text {, and }} r_{i}$ is the period-specific maximum rate of annual population growth at low levels of abundance. Periods indexed by $i$ span multiple years indexed by $t$, and we used this structure to model temporal shifts in $K$ and $r$ (see below). $Z$ is a shape parameter that determines both the rate at which population growth is slowed with increasing abundance and the abundance at which production is maximized. Larger values of $Z$ cause the population growth rate to fall faster and production to be maximized at higher levels of abundance. The USA MMPA defines a depleted stock of marine mammals as a stock whose abundance is less than that which maximizes its production 1 . This may be the maximum net productivity level (MNPL) and, as a proportion of $K$, it can be approximated from a function of $Z$ (Smith 1983):

$$
\text { MNPL }=(Z+1)^{-1 / Z}
$$

Eq. (2) cannot be rearranged to provide an analytical solution for $Z$ in terms of MNPL.

1Public Law 92-522, 21 October 1972 and amendments, 16 U.S.C. $\S 1362$ 
Table 1. Stenella attenuata attenuata and S. longirostris orientalis. Bycatch kill and abundance estimates (ind. $\times 10^{3}$ ) used to assess the status of dolphin stocks in the eastern tropical Pacific Ocean as of 2002. Values are expectations and those inside parentheses are coefficients of variation

\begin{tabular}{|c|c|c|c|c|}
\hline \multirow[t]{2}{*}{ Year } & \multicolumn{2}{|c|}{$\begin{array}{c}\text { Northeastern offshore } \\
\text { spotted }\end{array}$} & \multicolumn{2}{|c|}{ Eastern spinner } \\
\hline & Bycatch & Abundance & Bycatch & Abundance \\
\hline 1959 & $15.9(0.53)$ & & $6.5(0.47)$ & \\
\hline 1960 & $344.0(0.52)$ & & $138.4(0.47)$ & \\
\hline 1961 & $366.0(0.48)$ & & $153.5(0.43)$ & \\
\hline 1962 & $141.0(0.42)$ & & $62.2(0.40)$ & \\
\hline 1963 & $158.2(0.36)$ & & $69.4(0.37)$ & \\
\hline 1964 & $272.3(0.28)$ & & $112.7(0.34)$ & \\
\hline 1965 & $318.5(0.29)$ & & $132.5(0.34)$ & \\
\hline 1966 & $244.1(0.22)$ & & $107.8(0.33)$ & \\
\hline 1967 & $171.8(0.23)$ & & $72.2(0.33)$ & \\
\hline 1968 & $161.2(0.22)$ & & $65.7(0.33)$ & \\
\hline 1969 & $271.5(0.22)$ & & $110.4(0.35)$ & \\
\hline 1970 & $218.7(0.22)$ & & $104.5(0.33)$ & \\
\hline 1971 & $111.3(0.22)$ & & $60.1(0.32)$ & \\
\hline 1972 & $168.1(0.17)$ & & $88.5(0.32)$ & \\
\hline 1973 & $49.9(0.18)$ & & $18.4(0.16)$ & \\
\hline 1974 & $37.4(0.11)$ & & $17.8(0.11)$ & \\
\hline 1975 & $49.4(0.18)$ & & $17.1(0.11)$ & \\
\hline 1976 & $20.4(0.23)$ & & $14.7(0.12)$ & \\
\hline 1977 & $5.9(0.12)$ & & $1.8(0.12)$ & \\
\hline 1978 & $4.2(0.20)$ & & $1.1(0.11)$ & \\
\hline 1979 & $4.8(0.17)$ & $708(0.28)$ & $1.5(0.24)$ & $449(0.35)$ \\
\hline 1980 & $6.5(0.15)$ & $740(0.25)$ & $1.1(0.20)$ & $271(0.38)$ \\
\hline 1981 & $8.1(0.19)$ & & $2.3(0.28)$ & \\
\hline 1982 & $9.3(0.17)$ & $605(0.29)$ & $2.6(0.33)$ & $285(0.39)$ \\
\hline 1983 & $2.4(0.27)$ & $548(0.34)$ & $0.7(0.38)$ & $619(0.40)$ \\
\hline 1984 & $7.8(0.19)$ & & $6.0(0.52)$ & \\
\hline 1985 & $26.0(0.12)$ & & $8.9(0.16)$ & \\
\hline 1986 & $52.0(0.16)$ & $494(0.22)$ & $19.5(0.19)$ & $536(0.35)$ \\
\hline 1987 & $35.4(0.12)$ & $501(0.19)$ & $10.4(0.11)$ & $443(0.30)$ \\
\hline 1988 & $26.6(0.10)$ & $868(0.24)$ & $18.8(0.09)$ & $636(0.28)$ \\
\hline 1989 & $28.9(0.11)$ & $954(0.23)$ & $15.2(0.11)$ & $734(0.41)$ \\
\hline 1990 & $22.6(0.11)$ & $666(0.35)$ & $5.4(0.18)$ & $459(0.30)$ \\
\hline 1991 & $9.0(0.11)$ & & $5.9(0.13)$ & \\
\hline 1992 & $4.7(0.07)$ & & $2.8(0.06)$ & \\
\hline 1993 & $1.1(0.08)$ & & $0.8(0.08)$ & \\
\hline 1994 & $0.9(0.07)$ & & $0.7(0.11)$ & \\
\hline 1995 & $1.0(0.00)$ & & $0.7(0.00)$ & \\
\hline 1996 & $0.8(0.00)$ & & $0.5(0.00)$ & \\
\hline 1997 & $0.7(0.00)$ & & $0.4(0.00)$ & \\
\hline 1998 & $0.3(0.00)$ & $676(0.14)$ & $0.4(0.00)$ & $557(0.22)$ \\
\hline 1999 & $0.4(0.00)$ & $600(0.16)$ & $0.4(0.00)$ & $361(0.25)$ \\
\hline 2000 & $0.3(0.00)$ & $647(0.21)$ & $0.3(0.00)$ & $428(0.22)$ \\
\hline 2001 & $0.6(0.00)$ & & $0.5(0.00)$ & \\
\hline 2002 & $0.6(0.00)$ & & $0.5(0.00)$ & \\
\hline
\end{tabular}

We used Eq. (1) to build a set of 6 models. Our 'reference model' is the simplest, and for this model we assumed that the dynamics of an individual stock were governed by one $K$ and one $r$ (i.e. these parameters did not change during the period 1959 to 2002). We also assumed that the expected kills reported in Table 1 are unbiased estimates of the true kills. Next, we built a model with 2 carrying capacities ( $K_{1}$ and $K_{2} ; 2-K$ model) and another model with 2 maximum rates of population growth ( $r_{1}$ and $r_{2} ; 2-r$ model); these represent change-point models. For each of these models, we introduced an additional parameter $(\delta)$ that identifies the year which separates Period 1 (1959 to $\delta$ ) from Period $2(\delta+1$ to 2002$)$. For the $2-K$ and $2-r$ models, we assumed that the expected kills reported in Table 1 are unbiased estimates of the true kills. Finally, we constructed 3 models (each with one $K$ and one $r$ ) under the assumption that the expected kills reported in Table 1 underestimate the true kills. For these models, we respectively assumed that (1) in all years the true kills are estimated by values equal to 1.5 times those reported in Table 1, (2) in all years the true kills are estimated by values equal to 2.0 times those reported in Table 1, and (3) during 1992 to 2002 the true kills are estimated by values equal to 2.0 times those reported in Table 1 (in this case, we assumed that the expectations reported for 1959 to 1991 are unbiased). We used the coefficients of variation for estimated kills of dolphins reported in Table 1 to specify levels of prior uncertainty for all 6 of our models; this allows us to fully incorporate uncertainty in the level of dolphin kill from sampling error into the analysis. We parameterized all models by assuming that both dolphin stocks were at their carrying capacities in 1958 ( $K_{1}$ in the 2-K model and $K$ in all other models).

Parameter estimation and model comparison. We used Bayesian methods to fit our models and make comparisons among them. We used information from a variety of sources to specify prior distributions that were intended to bracket biologically reasonable parameter spaces but be uninformative within those spaces (Table 2). Our prior distributions for $K$ were established by inspecting the results of previous modeling efforts (e.g. Wade 1994), and were selected to be uniform distributions across the plausible range of the posterior distribution for all the models. Any prior dis-

Table 2. Stenella attenuata attenuata and S. longirostris orientalis. Prior distributions for parameters in our generalized logistic models. Numbers for carrying capacity $(K)$ are reported as ind. $\times 10^{3}$. MNPL: maximum net productivity level; $r$ : maximum rate of annual population growth; $\delta$ : year which separates $K_{1}$ from $K_{2}$ or $r_{1}$ from $r_{2}$ i U: uniform distribution; DU: discrete uniform distribution

\begin{tabular}{|lcc|}
\hline Model & Northeastern offshore spotted & Eastern spinner \\
\hline$K$ or $K_{1}$ & $\mathrm{U}(2000,7500)$ & $\mathrm{U}(1000,3500)$ \\
$K_{2}$ & $\mathrm{U}(0,7500)$ & $\mathrm{U}(0,5500)$ \\
$r$ & $\mathrm{U}(0.00,0.08)$ & $\mathrm{U}(0.00,0.08)$ \\
$r_{2}$ & $\mathrm{U}(-0.08,0.08)$ & $\mathrm{U}(-0.08,0.08)$ \\
MNPL & $\mathrm{U}(0.5,0.8)$ & $\mathrm{U}(0.5,0.8)$ \\
$\delta$ & $\mathrm{DU}(1981,1999)$ & $\mathrm{DU}(1981,1999)$ \\
\hline
\end{tabular}


tribution that is approximately uniform at least across the region where the likelihood function is not negligible for a quantity of interest will be non-informative with respect to that quantity (Savage 1962); this was true of our prior distributions for $K$ for each model. We used results from Reilly \& Barlow (1986) to derive our prior distributions for $r$, but we also included the possibility of negative growth rates in the 2-r models. We used results from Taylor \& DeMaster (1993) to specify prior distributions for MNPL rather than $Z$, where MNPL is expressed as a fraction of $K$. This necessitated numerical solutions for $Z$ after sampling from the MNPL priors; for this we used Brent's method (e.g. Press et al. 1986). Our prior distributions for MNPL implied a prior distribution for $Z$ ranging from 1.0 to 11.2. We treated the bycatch kill estimates as prior information; therefore, the expected kills and coefficients of variation reported in Table 1 were used to specify log-normal prior distributions (1 distribution for each year) for the kills. For the models with higher kills, we scaled the entire prior distribution for the bycatch kill up by a factor of 1.5 or 2.0, as appropriate. The prior distribution for $\delta$ was chosen to be uniform across the range of years for which there was abundance data available. We specified a likelihood function by assuming that the abundance estimates from the research surveys were samples from log-normal distributions (again 1 distribution for each year, with expectations and variances determined by the values reported in Table 1). We simulated posterior distributions with the sampling-importance resampling algorithm (Rubin 1988), with >200 000000 samples drawn from the prior distribution, and 10000 values in the second sample. Diagnostic criteria used to confirm convergence were (1) >9900 unique values in the second sample and (2) no particular initial sample could occur in the second sample more than 5 times.

The 6 models we developed from Eq. (1) provide a framework in which to compare hypotheses for the lack of recovery (Gerrodette \& Forcada 2005) by northeastern offshore spotted and eastern spinner dolphins. Our reference model is generic and does not represent a specific hypothesis. The 'extra mortality' models represent hypotheses in which fishery effects may prevent recovery, and the $2-K$ model represents a hypothesis in which ecosystem effects may prevent recovery. The 2-r model represents fishery effects, ecosystem effects, or effects from complex population dynamics. All such effects (acting independently or in combination) could conceivably cause $r$ to shift. We used Bayes factors (Kass \& Raftery 1995) to compare 5 alternative models (the 2-K, 2-r, and extra mortality models) with our reference model. We assign equal prior probability to each model; in this case, the Bayes factor also represents the posterior odds ratio (the probability of one model divided by the probability of a second model). These comparisons, therefore, quantify the degrees to which the prior information about bycatch and the abundance estimates reported in Table 1 support each model and give a posterior probability of each model versus another. Note that there are many mechanisms which might plausibly lead to fishery and ecosystem effects, but our models are simple and do not provide explicit, mathematical descriptions of such mechanisms. Thus, our Bayes factors are only indicative of the types of effects that may prevent recovery of the 2 dolphin stocks. We used the probabilities provided by the Bayes factors to summarize the results across all models by creating model-averaged posterior distributions for the parameters of interest, with the results from each model weighted by its posterior probability.

\section{RESULTS}

\section{Abundance and status of northeastern offshore spotted dolphins}

The data provided in Table 1 was informative for estimating the carrying capacity and maximum rate of population growth for northeastern offshore spotted dolphins. The posterior distributions of both $K$ (including $K_{1}$ and $K_{2}$ in the 2-K model) and $r$ (including $r_{1}$ and $r_{2}$ in the 2-r model) were generally different from their respective prior distributions (Table 3 ). The modelaveraged population trajectory, with $90 \%$ credible intervals for abundance in each year, indicates that the current population is approximately one-fifth of its initial abundance (Fig. 1). The details of each model's fit to the abundance data are shown in Fig. 2 . $K$ was a relatively well-estimated parameter; the posterior distributions of $K$ were much narrower than their priors, and shrinkage usually occurred in both tails. The posterior distributions of $r$ were also narrower than their priors, but here shrinkage usually occurred in the right-hand tails (although note that most of the priors for $r$ did not allow for negative growth rates) (Fig. 3). Thus, the posterior medians of $r$ were usually much less than their prior medians.

All 6 models provided similar fits to the abundance estimates in Table 1. However, the 2 models with extra mortality prior to 1992 had higher abundance than the other models in the 1970s and 1980s, and lower abundance in the 1990s (Fig. 2); they also estimated larger $K$ and $r$ values. The 2 change-point models suggested greater uncertainty in the parameters that changed. The reference model estimated initial abundance of northeastern offshore spotted dolphins to have a $95 \%$ credible interval from 3.0 to 3.9 million dolphins. How- 
Table 3. Stenella attenuata attenuata and S. longirostris orientalis. Summary of the posterior distributions for northeastern offshore spotted and eastern spinner dolphins. Value in the top row for each parameter is the posterior median, and the parenthetical pair below it represents the $95 \%$ credible interval (there is a 0.95 probability that the true value lies within the interval). The space has been left blank for parameters that are not applicable to that model. Vertical arrows: departures of the posterior distribution from the prior distribution for all the explicit parameters of the models (first 6 rows). For the posterior medians, the arrows identify estimates that have moved greater than $10 \%$ of the entire prior range from the prior mean. For the intervals, the arrows represent posterior interval bounds that are within the $80 \%$ credible interval of the prior distribution. Posterior probabilities were also calculated for additional output parameters (last 5 rows) from the joint posterior distribution for the model parameters. Carrying capacity $(K)$ and abundance $(N)$ are reported in ind. $\times 10^{3}$. Note that, for $\mathrm{N}_{2002}$ /MNPL, MNPL (maximum net productivity level) is expressed here not as a fraction of $K$, but as numbers of individuals. MNPL 2 represents the MNPL associated with $K_{2}$. $r$ : maximum rate of annual population growth. $C$ : vector of the annual number of deaths caused by fishing for the years specified that is multiplied by the value of 1.5 or 2.0. See Table 2 for other parameter definitions

\begin{tabular}{|c|c|c|c|c|c|c|c|}
\hline Parameter & Reference & $2-K$ & $2-r$ & $1.5 \cdot \bar{C}_{1959-2002}$ & $2.0 \cdot \bar{C}_{1959-2002}$ & $2.0 \cdot \bar{C}_{1992-2002}$ & Model averaged \\
\hline \multicolumn{8}{|c|}{ Northeastern offshore spotted } \\
\hline$K$ or $K_{1}$ & $\begin{array}{c}3500^{\downarrow} \\
\left(3049^{\uparrow}, 3914^{\downarrow}\right)\end{array}$ & $\begin{array}{c}3476^{\downarrow} \\
\left(2921^{\uparrow}, 4259^{\downarrow}\right)\end{array}$ & $\begin{array}{c}3299^{\downarrow} \\
\left(2582,3864^{\downarrow}\right)\end{array}$ & $\begin{array}{c}4794^{\downarrow} \\
\left(4198^{\uparrow}, 5406^{\downarrow}\right)\end{array}$ & $\begin{array}{c}6000 \\
\left(5252^{\uparrow}, 6725^{\downarrow}\right)\end{array}$ & $\begin{array}{c}3477^{\downarrow} \\
\left(3027^{\uparrow}, 3909^{\downarrow}\right)\end{array}$ & $\begin{array}{c}3653^{\downarrow} \\
\left(2842^{\uparrow}, 5740^{\downarrow}\right)\end{array}$ \\
\hline$K_{2}$ & & $\begin{array}{c}3682 \\
\left(553^{\uparrow}, 7308\right)\end{array}$ & & & & & \\
\hline$r$ or $r_{1}$ & $\begin{array}{c}0.016^{\downarrow} \\
\left(0.002,0.036^{\downarrow}\right)\end{array}$ & $\begin{array}{c}0.017^{\downarrow} \\
\left(0.002,0.048^{\downarrow}\right)\end{array}$ & $\begin{array}{c}0.026^{\downarrow} \\
\left(0.002,0.069^{\downarrow}\right)\end{array}$ & $\begin{array}{c}0.025^{\downarrow} \\
\left(0.006,0.045^{\downarrow}\right)\end{array}$ & $\begin{array}{c}0.033^{\downarrow} \\
\left(0.013^{\uparrow}, 0.053^{\downarrow}\right)\end{array}$ & $\begin{array}{c}0.017^{\downarrow} \\
\left(0.002,0.037^{\downarrow}\right)\end{array}$ & $\begin{array}{c}0.021^{\downarrow} \\
\left(0.002,0.054^{\downarrow}\right)\end{array}$ \\
\hline$r_{2}$ & & & $\begin{array}{c}0.000 \\
\left(-0.073^{\uparrow}, 0.063^{\downarrow}\right)\end{array}$ & & & & \\
\hline$\delta$ & & $\begin{array}{c}1990 \\
(1981,1999)\end{array}$ & $\begin{array}{c}1993 \\
(1981,1999)\end{array}$ & & & & \\
\hline MNPL & $\begin{array}{c}0.641 \\
(0.506,0.791)\end{array}$ & $\begin{array}{c}0.632 \\
(0.505,0.791)\end{array}$ & $\begin{array}{c}0.632 \\
(0.505,0.791)\end{array}$ & $\begin{array}{c}0.634 \\
(0.506,0.792)\end{array}$ & $\begin{array}{c}0.638 \\
(0.505,0.792)\end{array}$ & $\begin{array}{c}0.637 \\
(0.505,0.791)\end{array}$ & $\begin{array}{c}0.641 \\
(0.505,0.791)\end{array}$ \\
\hline$N_{2002}$ & $\begin{array}{c}690 \\
(568,856)\end{array}$ & $\begin{array}{c}683 \\
(560,849)\end{array}$ & $\begin{array}{c}643 \\
(471,868)\end{array}$ & $\begin{array}{c}710 \\
(575,886)\end{array}$ & $\begin{array}{c}733 \\
(588,911)\end{array}$ & $\begin{array}{c}689 \\
(562,853)\end{array}$ & $\begin{array}{c}689 \\
(530,870)\end{array}$ \\
\hline$N_{2002} / K$ & $\begin{array}{c}0.197 \\
(0.150,0.273)\end{array}$ & $\begin{array}{c}0.197 \\
(0.149,0.273)\end{array}$ & $\begin{array}{c}0.197 \\
(0.138,0.277)\end{array}$ & $\begin{array}{c}0.149 \\
(0.109,0.205)\end{array}$ & $\begin{array}{c}0.122 \\
(0.089,0.168)\end{array}$ & $\begin{array}{c}0.198 \\
(0.149,0.273)\end{array}$ & $\begin{array}{c}0.194 \\
(0.118,0.274)\end{array}$ \\
\hline$N_{2002} / K_{2}$ & & $\begin{array}{c}0.189 \\
(0.089,1.090)\end{array}$ & & & & & \\
\hline$N_{2002} / \mathrm{MNPL}$ & $\begin{array}{l}\mathrm{L} \quad 0.312 \\
(0.213,0.456)\end{array}$ & $\begin{array}{c}0.313 \\
(0.214,0.462)\end{array}$ & $\begin{array}{c}0.312 \\
(0.203,0.463)\end{array}$ & $\begin{array}{c}0.236 \\
(0.157,0.339)\end{array}$ & $\begin{array}{c}0.193 \\
(0.132,0.277)\end{array}$ & $\begin{array}{c}0.313 \\
(0.212,0.463)\end{array}$ & $\begin{array}{c}0.308 \\
(0.176,0.460)\end{array}$ \\
\hline$N_{2002} / \mathrm{MNPL}$ & & $\begin{array}{c}0.299 \\
(0.129,1.908)\end{array}$ & & & & & \\
\hline \multicolumn{8}{|c|}{ Eastern spinner } \\
\hline$K$ or $K_{1}$ & $\begin{array}{c}1673^{\downarrow} \\
\left(1374^{\uparrow}, 1901^{\downarrow}\right)\end{array}$ & $\begin{array}{c}1645^{\downarrow} \\
\left(1244^{\uparrow}, 1899^{\downarrow}\right)\end{array}$ & $\begin{array}{c}1457^{\downarrow} \\
\left(1099,1864^{\downarrow}\right)\end{array}$ & $\begin{array}{c}2292^{\downarrow} \\
\left(1918^{\uparrow}, 2604^{\downarrow}\right)\end{array}$ & $\begin{array}{c}2875 \\
\left(2429^{\uparrow}, 3287\right)\end{array}$ & $\begin{array}{c}1668^{\downarrow} \\
\left(1370^{\uparrow}, 1903^{\downarrow}\right)\end{array}$ & $\begin{array}{c}1795^{\downarrow} \\
\left(1190,3010^{\downarrow}\right)\end{array}$ \\
\hline$K_{2}$ & & $\begin{array}{c}2294 \\
(305,5344)\end{array}$ & & & & & \\
\hline$r$ or $r_{1}$ & $\begin{array}{c}0.014^{\downarrow} \\
\left(0.001,0.041^{\downarrow}\right)\end{array}$ & $\begin{array}{c}0.016^{\downarrow} \\
\left(0.001,0.067^{\downarrow}\right)\end{array}$ & $\begin{array}{c}0.037^{\downarrow} \\
(0.002,0.077)\end{array}$ & $\begin{array}{c}0.017^{\downarrow} \\
\left(0.001,0.043^{\downarrow}\right)\end{array}$ & $\begin{array}{c}0.021^{\downarrow} \\
\left(0.002,0.047^{\downarrow}\right)\end{array}$ & $\begin{array}{c}0.014^{\downarrow} \\
\left(0.001,0.042^{\downarrow}\right)\end{array}$ & $\begin{array}{c}0.022^{\downarrow} \\
\left(0.001,0.070^{\downarrow}\right)\end{array}$ \\
\hline$r_{2}$ & & & $\begin{array}{c}-0.014 \\
\left(-0.076,0.042^{\downarrow}\right)\end{array}$ & & & & \\
\hline$\delta$ & & $\begin{array}{c}1990 \\
(1981,1999)\end{array}$ & $\begin{array}{c}1991 \\
(1981,1999)\end{array}$ & & & & \\
\hline MNPL & $\begin{array}{c}0.631 \\
(0.505,0.792)\end{array}$ & $\begin{array}{c}0.629 \\
(0.505,0.790)\end{array}$ & $\begin{array}{c}0.625 \\
(0.506,0.790)\end{array}$ & $\begin{array}{c}0.636 \\
(0.506,0.792)\end{array}$ & $\begin{array}{c}0.636 \\
(0.505,0.791)\end{array}$ & $\begin{array}{c}0.631 \\
(0.505,0.790)\end{array}$ & $\begin{array}{c}0.637 \\
(0.505,0.791)\end{array}$ \\
\hline$N_{2002}$ & $\begin{array}{c}503 \\
(399,660)\end{array}$ & $\begin{array}{c}493 \\
(376,649)\end{array}$ & $\begin{array}{c}438 \\
(310,622)\end{array}$ & $\begin{array}{c}501 \\
(391,667)\end{array}$ & $\begin{array}{c}505 \\
(387,676)\end{array}$ & $\begin{array}{c}500 \\
(396,660)\end{array}$ & $\begin{array}{c}470 \\
(371,660)\end{array}$ \\
\hline$N_{2002} / K$ & $\begin{array}{c}0.300 \\
(0.224,0.460)\end{array}$ & $\begin{array}{c}0.300 \\
(0.220,0.466)\end{array}$ & $\begin{array}{c}0.302 \\
(0.196,0.467)\end{array}$ & $\begin{array}{c}0.218 \\
(0.158,0.335)\end{array}$ & $\begin{array}{c}0.175 \\
(0.123,0.269)\end{array}$ & $\begin{array}{c}0.297 \\
(0.222,0.463)\end{array}$ & $\begin{array}{c}0.288 \\
(0.155,0.455)\end{array}$ \\
\hline$N_{2002} / K_{2}$ & & $\begin{array}{c}0.350 \\
(0.088,1.090)\end{array}$ & & & & & \\
\hline$N_{2002} / \mathrm{MNPL}$ & $\begin{array}{l}\mathrm{L} \quad 0.478 \\
(0.315,0.781)\end{array}$ & $\begin{array}{c}0.482 \\
(0.316,1.315)\end{array}$ & $\begin{array}{c}0.484 \\
(0.287,0.769)\end{array}$ & $\begin{array}{c}0.348 \\
(0.226,0.339)\end{array}$ & $\begin{array}{c}0.279 \\
(0.177,0.446)\end{array}$ & $\begin{array}{c}0.477 \\
(0.315,0.789)\end{array}$ & $\begin{array}{c}0.461 \\
(0.230,0.760)\end{array}$ \\
\hline$N_{2002} / \mathrm{MNPL}$ & & $\begin{array}{c}0.299 \\
(0.128,2.321)\end{array}$ & & & & & \\
\hline
\end{tabular}




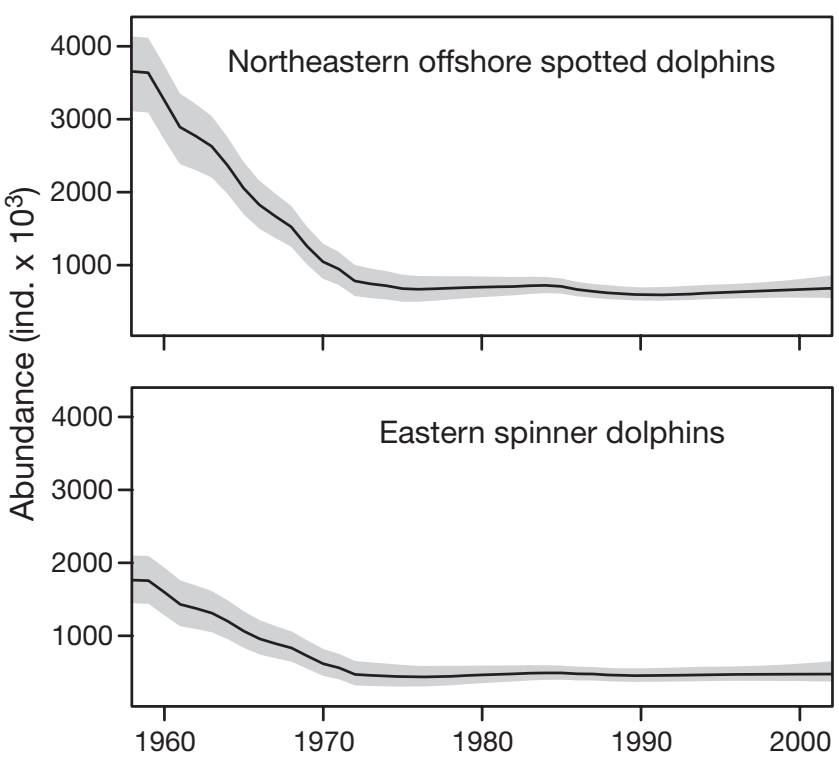

Fig. 1. Stenella attenuata attenuata and S. longirostris orientalis. Model-averaged estimated population trajectories from 1958 to 2002. Line respresents the median posterior population size in each year. Gray region represents the $90 \%$ credible interval for population size in each year (there is a 0.90 probability that the true value lies within the interval)

ever, pooling results from all the models expanded this range considerably at the higher end due to the models with extra mortality. The model-averaged posterior distribution for the initial abundance had a $95 \%$ credible interval that ranged from 2.8 to 5.7 million dolphins. The model-averaged posterior distribution for the maximum population growth rate (using $r_{1}$ from the $2-r$ model in the model average) estimated a 0.83 probability that the maximum growth rate was less than $3 \% \mathrm{yr}^{-1}$, and a 0.93 probability that it was less than $4 \% \mathrm{yr}^{-1}$.

Despite these general conclusions noted above, the posterior distributions of both $K$ and $r$ varied among models, and the information content of the abundance estimates was dependent on model choice (Table 3). Uncertainty in $K$ and $r$ was greatest for the 2 changepoint models. These models also showed substantial uncertainty in the estimated times at which $K$ and $r$ may have changed. In general, the posterior distributions for bycatch recapitulated the prior distributions, and those results have not been presented.

All 6 models supported the conclusion that in 2002 the northeastern stock of offshore spotted dolphins was depleted relative to its initial abundance (Fig. 4, Table 3). Uncertainty in the degree of depletion (again, relative to the initial abundance) arose from uncertainty in MNPL. The posterior distributions of MNPL were not very different from their prior distributions and were nearly uniform over the range 0.5 to 0.8 ,

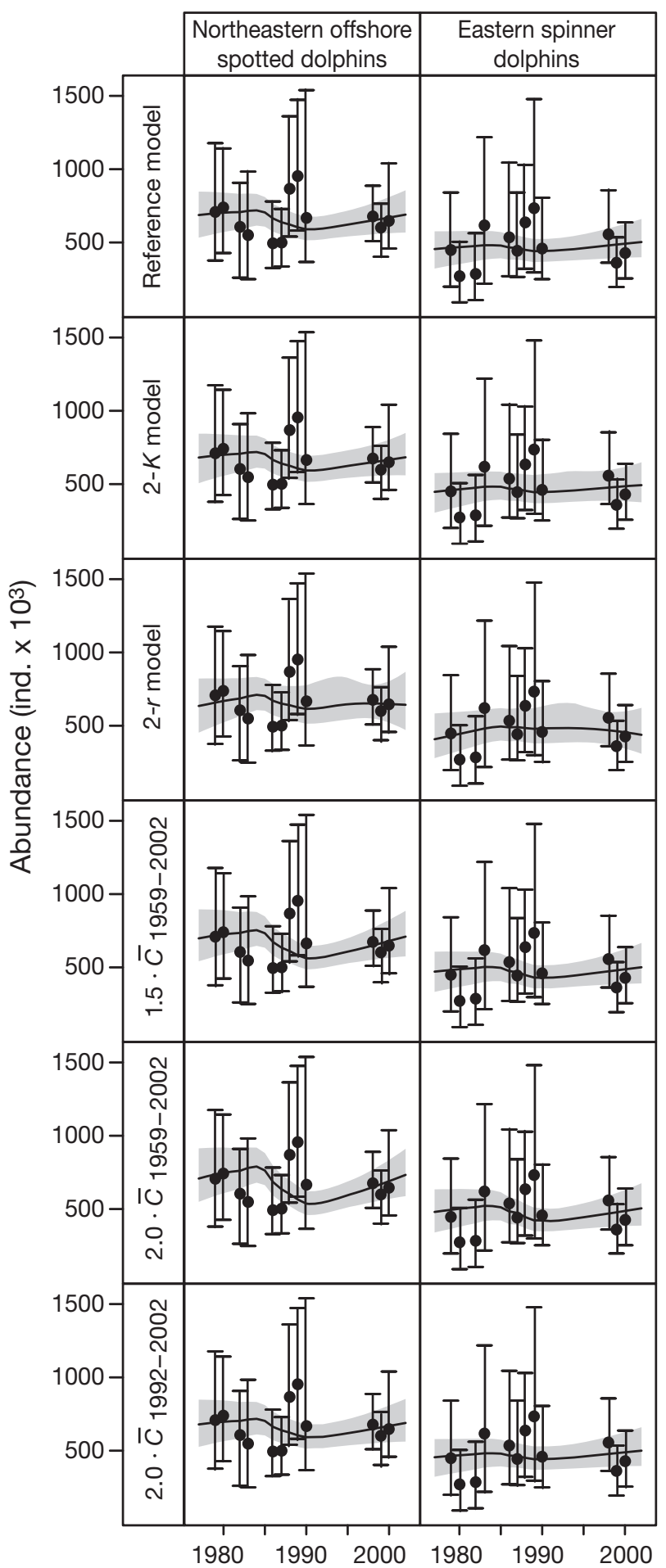

Fig. 2. Stenella attenuata attenuata and S. longirostris orientalis. Fits of the models to the abundance estimates $(\bullet)$ provided in Table 1. Solid lines connect median abundance estimates; grey region represents the $90 \%$ credible intervals for population size in each year. Error bars are $95 \%$ confidence limits. $K$ : carrying capacity; $r$ : maximum rate of annual population growth; $\bar{C}$ : vector of the annual number of deaths caused by fishing for the years specified that is multiplied by the value of 1.5 or 2.0 

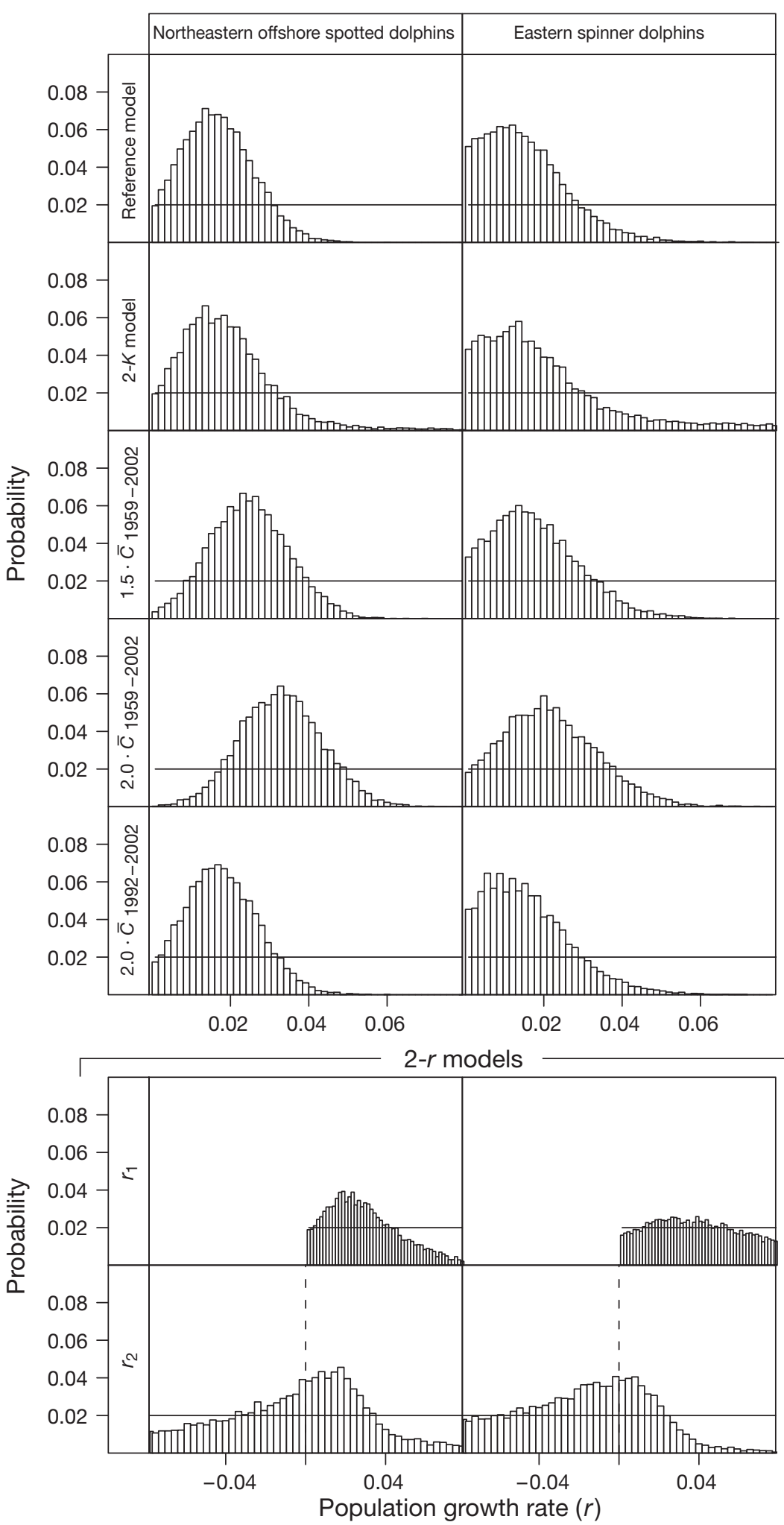

Fig. 3. Stenella attenuata attenuata and S. longirostris orientalis. Posterior and prior distributions for $r$, the maximum population growth rate parameter. The prior distribution is plotted as a line and the posterior distribution is plotted as a histogram. Note that the distributions for the 2- $r$ models are plotted on a different scale. See Fig. 2 for definitions with a higher probability of lower values than of higher values (Table 3). Within any given model, depletion was least severe when MNPL $=0.5$ defined the reference point and most severe when MNPL $=0.8$ defined the reference point. Variations in $K$ within and between models were further sources of uncertainty in the degree of depletion. Within models, depletion was less severe for values of $K$ below the posterior median and more severe for values of $K$ above the median. Between models, uncertainty in the degree of depletion derived from modelspecific differences in the posteriors of $K$. The 2 models with extra mortality prior to 1992, not surprisingly, suggested greater degrees of depletion than the other models (Fig. 4). Nevertheless, to reiterate the general result, all of the models estimated that in 2002 the abundance of northeastern offshore spotted dolphins was less than $30 \%$ of the initial abundance of this stock (Fig. 1, Table 3) and was between about 500000 and 900000 individuals (Table 3). The model-averaged posterior distribution estimated a probability of 1.0 that the population was below MNPL (referenced to initial abundance), with a $95 \%$ credible interval for the depletion level $\left(N_{2002} / K\right)$ of 0.12 to 0.27 (Fig. 5).

The $2-K$ model facilitated consideration of whether the northeastern stock of offshore spotted dolphins was depleted relative to a carrying capacity that was determined some time after the development of the purse-seine fishery. When MNPL was treated as a proportion of $K_{2}$, there was a small probability $(0.15)$ that in 2002 the stock was not depleted relative to $K_{2}$ (Fig. 4).

\section{Abundance and status of eastern spinner dolphins}

Our results for eastern spinner dolphins were generally similar to those for northeastern offshore spotted dolphins, e.g. the posterior distributions for $K$ and $r$ were similarly different from their respective priors, and the 2 change-point models suggested greater uncertainty in the parameters that changed. However, 
there were some specific differences. In contrast to the case for northeastern offshore spotted dolphins, the Bayes factor indicated differences among models were not as great, perhaps due to the less precise abundance estimates available for eastern spinner dolphins (Table 4). However, similar to the spotted dolphin case, the models with extra mortality for the entire time period did fit the data least well. The reference model for eastern spinner dolphins suggested uncertainties in $K$ and $r$ that were similar in magnitude to those suggested by the $2-K$ model (Table 3 ). The one trajectory that shows a somewhat different dynamic from the other models is that of the 2-r model, where the population was showing recovery from the mid-1970s through the 1980s, but then began to slightly decline in the early 1990s (Fig. 2). This model also had the highest posterior probability, though the advantage was small and not great enough to consider this a clear 'best' model (Table 4). The reference model estimated a $95 \%$ credible interval for the initial abundance of eastern spinner dolphins of 1.4 to 1.9 million individuals. Summarizing results from all 6 models, the modelaveraged posterior distribution for the initial abundance of eastern spinner dolphins had a $95 \%$ credible interval that ranged from 1.2 to 3.0 million individuals. The model-averaged posterior distribution for the maximum population growth rate (using $r_{1}$ from the 2-r model in the model average) estimated a 0.77 probability that it was less than $3 \% \mathrm{yr}^{-1}$, and a 0.86 probability that it was less than $4 \% \mathrm{yr}^{-1}$ (Fig. 5).

All 6 models supported the conclusion that in 2002 the stock of eastern spinner dolphins was depleted relative to its initial abundance. The reference model and the model-averaged posterior distribution estimated a probability of 0.998 and 0.999 , respectively, that the population was depleted (Fig. 5). The estimates of $N_{2002} / K$ indicate that the population was less than half of its initial abundance, with a $95 \%$ credible interval for the model-averaged posterior of 0.16 to 0.46 .

All 3 factors that contributed to uncertainty in the degree to which the northeastern stock of offshore

Table 4. Stenella attenuata attenuata and S. longirostris orientalis. Model comparisons based on Bayes factors. All comparisons are made to the model with the lowest posterior probability, which thus has a Bayes factor of 1.0. See Table 3 for parameter definitions

\begin{tabular}{lcc|} 
Model & Northeastern offshore spotted & Eastern spinner \\
\hline Reference & 7.0 & 2.0 \\
$2-K$ & 7.0 & 2.3 \\
$2-r$ & 5.5 & 2.6 \\
$1.5 \cdot \bar{C}_{1959-2002}$ & 2.8 & 1.5 \\
$2.0 \cdot \bar{C}_{1959-2002}$ & 1.0 & 1.0 \\
$2.0 \cdot \bar{C}_{1992-2002}$ & 7.2 & 2.2 \\
\hline
\end{tabular}

spotted dolphins was depleted also contributed to the same uncertainty for eastern spinner dolphins (and the nature of these contributions were similar) (Fig. 4). The posterior distributions of MNPL were not very different from their prior distributions and were nearly uniform over the range 0.5 to 0.8 , with a higher proability of lower values than of higher values (Table 3). Although there was little uncertainty about whether eastern spinner dolphins were depleted relative to their initial abundance, under the $2-K$ model there was a small probability $(0.24)$ that the population was not depleted relative to MNPL associated with current carrying capacity $\left(K_{2}\right)$, due to great uncertainty in the estimate of $K_{2}$ (the posterior distribution for this parameter was not different from the prior distribution). Viewed together, the results from all 6 models suggested that in 2002 the abundance of eastern spinner dolphins was between about 371000 and 651000 individuals (Table 3).

\section{Comparison of alternative models}

Our model comparisons were equivocal. This conclusion is based on categorizing Bayes factors as evidence in favor of one hypothesis over another that between 1 and 3 is evidence barely worth mentioning, between 3 and 20 is positive evidence, between 20 and 150 is strong evidence, and greater than 150 is very strong evidence (Kass \& Raftery 1995). In Table 4, we present Bayes factors relative to the model with the lowest posterior probability, which was for both species the model assumed to have mortality during 1959 to 2002 at twice the levels reported in Table 1. For northeastern offshore spotted dolphins, the reference model, the 2-K model, the 2- $r$ model, and the 1992 to 2002 extra mortality model were all 5.5 to 7.2 times more likely than this model, but about equally as likely among themselves (Table 4). Thus, for this stock there was a 'loser' but no clear 'winner' among the hypotheses. For eastern spinner dolphins, all of the alternative models had Bayes factors within the range 1-3, and so no hypothesis can be considered to have positive evidence for it compared to another hypothesis (Table 4).

\section{DISCUSSION}

\section{Status and trends of dolphin stocks as of 2002}

It is unlikely that, as of 2002, northeastern offshore spotted dolphins and eastern spinner dolphins had recovered to levels of abundance greater than thresholds marked by standard reference points for management. The MMPA stipulates that a marine mammal population is depleted if its abundance is less than that 

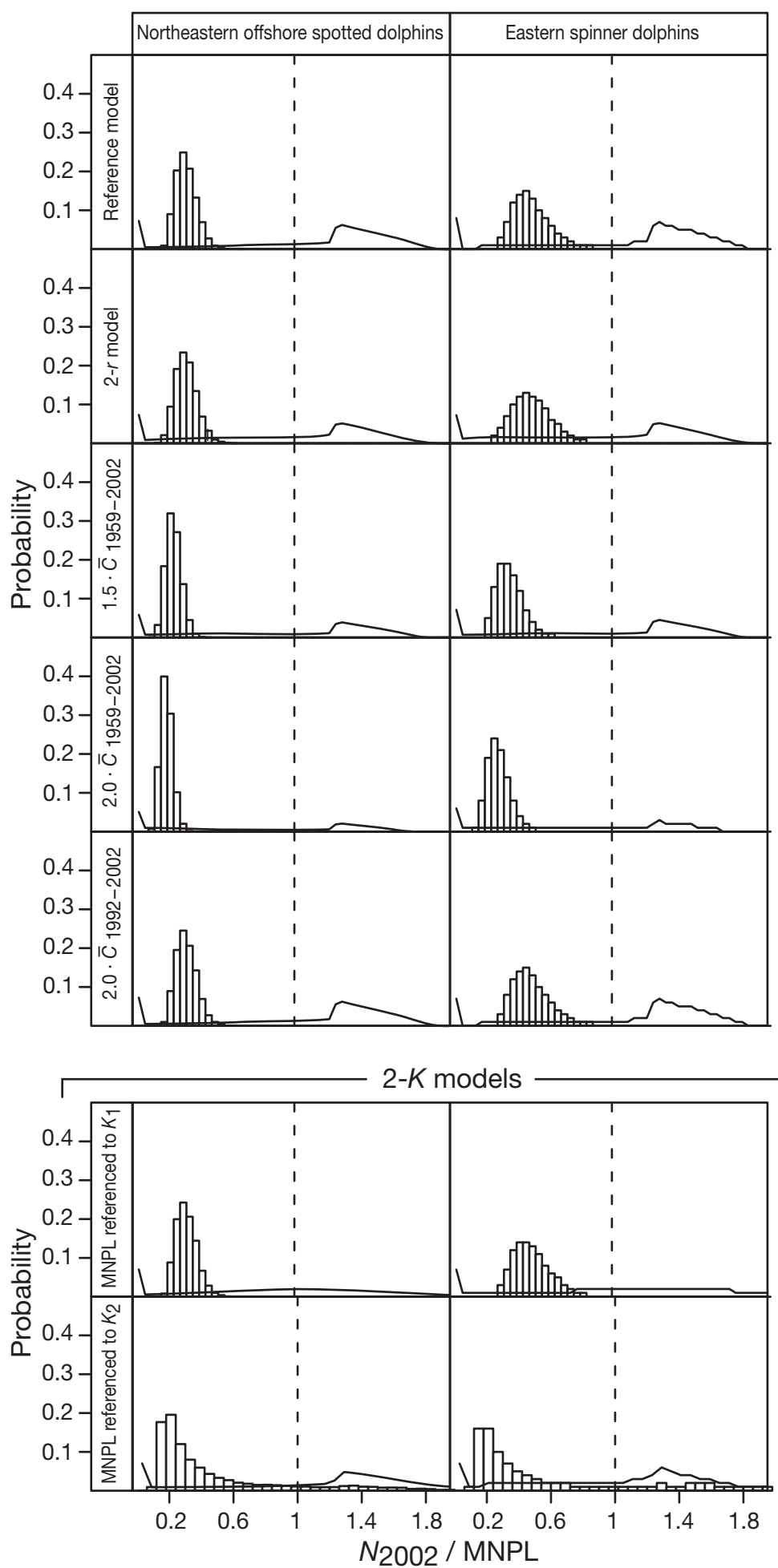

Fig. 4. Stenella attenuata attenuata and $S$. longirostris orientalis. Posterior (histogram) and prior (line) distributions for N2002/MNPL, the estimated depletion level relative to MNPL. Values $<1.0$ represent a population level considered depleted under the USA MMPA. The quantity N2002/MNPL is not an explicit parameter of the model; therefore we calculated the implicit prior distribution for this quantity from the joint prior distribution for the model parameters. Note the prior is relatively uninformative for this quantity, as desired. See Fig. 2 for definitions which maximizes its production (here taken as MNPL). The International Whaling Commission has established a similar reference point (Cooke 1995). While MNPL is clear in concept and well established in the fisheries literature, it is difficult to estimate for marine mammal populations because the data are usually insufficient (Gerrodette \& DeMaster 1990, Taylor \& DeMaster 1993). The dolphin stocks considered here are relatively well-studied marine mammal populations with 12 abundance estimates over a period of $21 \mathrm{yr}$, yet the posterior distributions of MNPL were similar to their priors. Long-lived, slowly reproducing animals such as cetaceans are expected to have MNPLs, expressed as fractions of $K$, above 0.5 (Eberhardt \& Siniff 1977, Fowler 1981, 1984). Although MNPL cannot be determined precisely for these populations, our analysis allowed us to integrate across considerable uncertainty in this parameter, and both populations were estimated to be depleted regardless of the value of MNPL. Our analyses show that there is little uncertainty in whether either population was depleted in 2002 relative to their initial abundance. In general, our results show that the abundance of northeastern offshore spotted dolphins was reduced to about onefifth, and eastern spinner dolphins to about one-third, of their pre-fishery levels (Fig. 1, Table 3). Our results are consistent with those of previous workers who used various other population-dynamics models and showed that both stocks were reduced to similar fractions of their historical abundances (Wade 1993, 1994, 1999, Alvarez-Flores 2002, Hoyle \& Maunder 2004).

There is an important caveat associated with assessing the status of these stocks. Reference points like those defined in the MMPA provide no guidance on which carrying capacity should be used to assess whether a stock is depleted, and in the analyses presented here we acknowledge the possibility that $K$ may have changed. In fact, the $2-K$ models for both northeastern offshore spotted and eastern spinner dolphins were as well supported as their respective reference models. Thus, we temper our general conclusions by admitting that there is a small probability that, relative to their respective estimates of $K_{2}$, neither stock was depleted in 2002. Nevertheless, even if these alternative reference points are adopted, there is substantially greater probability that neither stock had recovered. 
Next, we consider whether the 2 dolphin stocks could have been recovering in 2002. Accepting that both populations were well below their estimated carrying capacities and that the number of dolphins killed in the fishery is small relative to the abundance of each stock $(<0.1 \%$ for both), we expect both stocks to be recovering at or mated $r>0$ with all of the models that had a single maximum growth rate. While this is hardly surprising, given our prior distributions for $r$, our posterior distributions indicated that there was high probability that both stocks were recovering at rates less than $4 \% \mathrm{yr}^{-1}$, an accepted minimum default for dolphin populations with reproductive parameters (e.g. calving intervals) like those considered here (Reilly \& Barlow 1986, Wade 1998). Additionally, there was considerable probability that both stocks were recovering at rates less than $3 \% \mathrm{yr}^{-1}$. We estimated median recovery rates of 1.7 and $1.4 \% \mathrm{yr}^{-1}$ for northeastern offshore spotted and eastern spinner dolphins, respectively; we also estimated the probability that each recovery rate was $<3 \% \mathrm{yr}^{-1}$ as 0.83 and 0.77 , respectively. We do not know whether such low intrinsic growth rates are natural for these species or whether the low rates are due to other factors impeding the recovery of these stocks. The alternative models considered here were intended to shed light on this central question.

Results from the 2-r models indicate uncertainty in the degree to which each stock was recovering. These near their maximum population growth rates, $r$. We esti-

models acknowledge the possibility that the contemporary (as of 2002) dynamics of northeastern offshore spotted and eastern spinner dolphins are different than their historical dynamics. For the eastern spinner stock, contemporary growth rates $\left(r_{2}\right)$ seem likely to be less than historical growth rates $\left(r_{1}\right)$ and 'overall' growth rates (i.e. the rates estimated by models with a single $r$ ). With the 2-r models, we estimated approximately 50-50 odds (equal chances) that northeastern offshore spotted dolphins were recently growing or declining and 70-30 odds that eastern spinner dolphins were recently declining. We cannot discount these results, because the Bayes factors indicate that both of the 2-r models received about as much support as their respective reference models. Thus, we conclude that there is substantial uncertainty about whether either population was recovering in 2002. Our conclusion is consistent with those of Lennert-Cody et al. (2001) and Gerrodette \& Forcada (2005), who respectively analyzed abundance estimates derived from fishing- and research-vessel data and concluded that neither stock was recovering at expected rates.

\section{Causative factors for lack of recovery}

Our results were equivocal with respect to attributing the apparent lack of recovery of northeastern off-

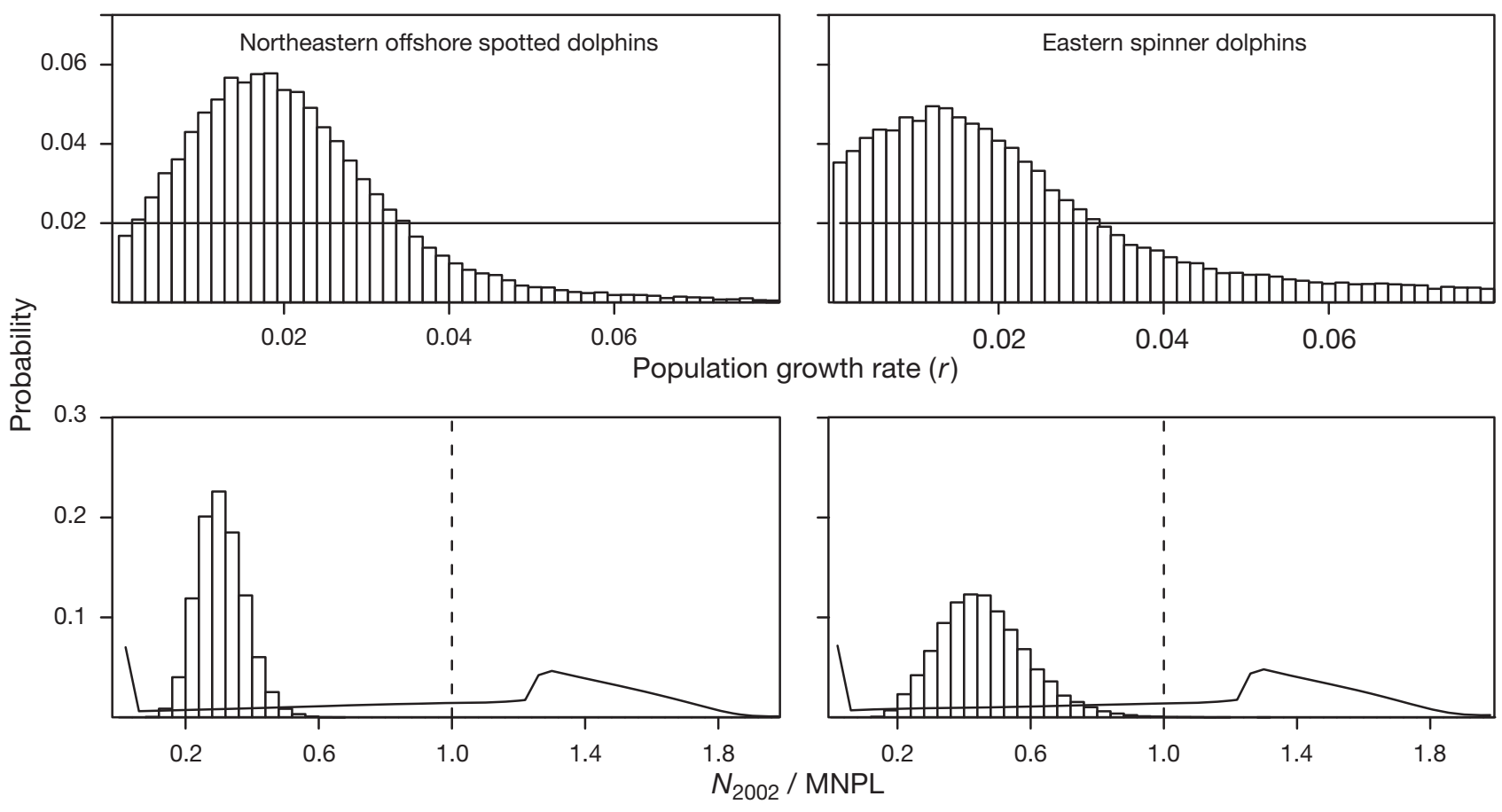

Fig. 5. Stenella attenuata attenuata and S. longirostris orientalis. Model-averaged posterior distributions for $r$ (the maximum population growth rate parameter) and for $N_{2002}$ /MNPL (maximum net productivity level), the estimated depletion level relative to MNPL. Model-averages were calculated using $r_{1}$ and MNPL referenced to $K_{1}$ (carrying capacity), respectively. Prior distribution is plotted as a line and the posterior distribution is plotted as a histogram 
shore spotted and eastern spinner dolphins to one or more causative factors. The Bayes factors indicated that hypothetical effects from the fishery and the ecosystem are equally supported. Our exploration of alternative hypotheses for the lack of recovery has not, however, been comprehensive, and other workers have identified potential and definitive fishery effects, while ecosystem effects have been elusive. We summarize this literature here and briefly discuss the strengths and weaknesses of our analytical approach.

A summary of recent research (Reilly et al. 2005) clearly illustrates that the purse-seine fishery has the capacity to affect dolphins beyond the direct mortality observed as bycatches. Chase and encirclement by purse-seine vessels and their speedboats may (1) cause changes in tissue chemistry that are associated with stress (Dizon et al. 2002, Southern et al. 2002, St. Aubin 2002), (2) elevate body temperatures and physically damage organ systems (Cowan \& Curry 2002, Pabst et al. 2002, St. Aubin 2002), (3) increase bioenergetic demands (Weihs 2004, Edwards 2006), and (4) influence swimming and schooling dynamics and behavior (Chivers \& Scott 2002, Mesnick et al. 2002, Santurtún \& Galindo 2002). While these physiological and behavioral changes may affect some individuals, they have not been shown to be common enough to have population-level consequences.

On the other hand, observations of mother-calf separation (Archer et al. 2001), declines in the numbers of calves (K. Cramer, W. Perryman, T. Gerrodette unpubl. data), and high fetal mortality (Perrin 1968) are population-level effects that directly address the lack of recovery. The calf deficits estimated from cows that were killed without their calves indicate minimum levels of additional mortality (about 14\% $\mathrm{yr}^{-1}$ ) not included in Table 1 (Archer et al. 2004). Reduced swimming ability and stamina of dolphin calves make mother-calf separation during fishing activity more likely, particularly during the first 6 mo of life (Edwards 2006, Noren \& Edwards 2007); the implication is that the cryptic loss of calves could be much larger. The proportion of calves declined between 1993 and 2003 for both northeastern offshore spotted and eastern spinner dolphins (K. Cramer, W. Perryman, T. Gerrodette unpubl. data). In the case of spotted dolphins, the number of dolphin sets negatively affected both the proportion of calves in the population and the length of time calves remained with their mothers. Fetal mortality in these dolphin populations is higher than in other mammals (Perrin 1968), but whether this is natural or due to effects of chase and encirclement is not yet known. Ultimately, although the studies identified here demonstrate both potential and definitive fishery effects, we do not know the degree to which these effects are having cumulative impacts on either dolphin stock. It is also clear that, over the past 5 or 6 decades during which the purse-seine fishery has operated, there have been changes in the structure of the pelagic ecosystem in the ETP, but these changes have not been linked to the lack of recovery by either dolphin stock. Changes in the physical and ecological environment of the ETP have been documented in (1) oceanography and climate (Fiedler 2002, McPhaden \& Zhang 2002, 2004), (2) plankton community structure and dynamics (Bidigare \& Ondrusek 1996, Landry et al. 1996), and (3) the abundances of other animals at middle and upper trophic levels (Ballance et al. 2002, Pitman et al. 2002, Watters et al. 2003, Hinke et al. 2004). Fiedler (2002) summarizes the findings of many other workers who have documented changes in the ETP. In general these changes have not been linked to the dynamics of northeastern offshore spotted and eastern spinner dolphins, because temporal variations in these ecosystem variables largely occur at El Niño scales, and to some degree at decadal scales, while this is not the case for temporal variations in dolphin abundance. Variations in dolphin abundance have, since the $1960 \mathrm{~s}$, primarily been driven by variations in the direct mortality caused by the purse-seine fishery. Nevertheless, the basic principles of ecology tell us that the physical and ecological environment ultimately determines how many dolphins can be supported by the pelagic ecosystem. For example, Watters et al. (2003) predict that a long-term, declining trend in the biomass of large phytoplankton (e.g. diatoms) in the ETP will cause the biomass of dolphins to decline regardless of potential fishery effects. Despite an inability to identify ecosystem effects on the recovery of either dolphin stock, this possibility cannot be dismissed.

We used an analytical approach that provides a logical framework for evaluating the competing hypotheses that attempt to explain the apparent lack of recovery by dolphin stocks in the ETP; this framework has at least 2 strengths. First, we used the same set of data to evaluate competing hypotheses (fishery versus ecosystem effects); this is not always feasible when a study is focused on considering a specific mechanism that might lead to an effect. Relying on a common data set leads to a more balanced competition between the hypotheses. A balanced treatment of alternative hypotheses in this case will not necessarily attribute delayed recovery to candidate causative factors with increased certainty, but such treatment may help temper inferences made from the competition of alternative hypotheses. For example, it would seem inappropriate to infer that fishery effects are solely responsible for a lack of recovery if 5 specific fishery effects have been in competition with only one ecosystem effect; equal weight would not have been given to the competing hypotheses. A second strength of our approach 
is that we are able to directly consider fishery and ecosystem effects at the population level (rather than, say, identify effects on individuals and forecast how these might accumulate to have population-level consequences). This is important because management decisions are often based on population-level responses, and making inferential leaps from individual-level effects to population-level responses can conceivably introduce additional error into the management process.

Our approach has at least 2 weaknesses. First, mortality and abundance estimates may simply not contain sufficient information to resolve the competition between hypotheses representing potential fishery and ecosystem effects, especially if there is insufficient contrast between the effects. This appears to be the case here; the Bayes factors provided roughly equal support to both categories of hypothesis. This weakness suggests that it might be useful to move towards 'integrated models' (e.g. Hoyle \& Maunder 2004) that synthesize information from other data sources. We are, however, uncertain whether such models, which are generally more complex than those used here, are better able to attribute a lack of recovery to causative factors because this ability will depend critically on the information content of the newly synthesized data. We have already mentioned the second weakness of our approach. Our generalized logistic models suggest feasible categories of effects, but these models do not explicitly describe the mechanisms that may make such effects operative. Identifying and understanding mechanisms is important because actions taken to mitigate broad categories of effects may be overly restrictive.

\section{Definition of dolphin-safe tuna and its implications for ecosystem-based management of the fishery}

The dolphin-safe label is a tuna-product labeling standard that was initially developed by environmental groups and tuna canners in the USA as a response to public concern over dolphin mortality in this fishery. It is intended to inform consumers that tuna products have been produced in an environmentally friendly and ecologically responsible way. Eco-labels are successfully used to market a diverse spectrum of other consumer goods, including such things as lumber, household cleaning products, cosmetics, packaging materials, and fuel. In 1990, the USA Dolphin Protection Consumer Information $\mathrm{Act}^{\underline{2}}$ legally defined dolphin-safe products to be those made from tunas cap-

²Public Law 101-627, 28 November 1990, 16 U.S.C. § 1385 tured in the ETP during fishing trips on which no sets were made on dolphin schools. In 1997, however, passage of the USA International Dolphin Conservation Program Act (IDCPA) ${ }^{3}$ raised the question of whether a less stringent definition of the labeling standard would be appropriate, where tuna caught by chasing and encircling dolphins could be called dolphin-safe as long as no dolphins were observed to be killed or seriously injured during an individual set. Given that directly observed mortality has been reduced to a low level relative to dolphin population size, the central issue in redefining dolphin-safe is whether the process of chasing, encircling, holding, and then releasing dolphins is harmful to the population. There is no question that chasing and encircling dolphins affects some individual dolphins negatively. The question posed in the IDCPA, however, was whether the effects on survival and reproduction are sufficiently strong to affect the population as a whole.

On December 31, 2002, the USA Secretary of Commerce determined that catching yellowfin tuna by chasing and encircling dolphins does not have a 'significant adverse impact' on the dolphin stocks considered here. The decision was challenged and overturned; the court found that the decision was based on political considerations more than science. In the USA, therefore, the original definition of dolphin-safe has been retained: tuna caught by methods that do not involve the chase and encirclement of dolphins. From the viewpoint of dolphin conservation, retaining this more conservative definition is clearly the most precautionary approach consistent with available data.

Dolphins are, however, only part of the larger ETP ecosystem. Other methods of fishing for tuna in the ETP result in bycatches of bony fishes, sharks, and turtles, but rarely dolphins (Hall 1998). In the developing paradigm of ecosystem-based fisheries management, framing conservation issues in the context of a 'significant adverse impact' on a single species (or 2 in this case) will not be sufficient. Revising the dolphin-safe definition in light of the ecosystem approach to management will likely require consideration of issues beyond the topic of dolphin recovery to more expansive, system-wide views of the potential ecological, social, and economic effects of regulatory and consumer marketing actions. Actions that change the allocation of fishing effort among the 3 types of purseseine sets (sets on dolphins, floating objects, or unassociated schools of tuna) or that change the allocation of fishing effort among the purse-seine and longline fleets will involve complex tradeoffs (Hinke et al. 2004).

${ }^{3}$ Public Law 105-42, 15 August 1997, 16 U.S.C. § 1361 
Acknowledgements. We thank D. Goodman, W. Perrin, M. Haddon, and M. McAllister for providing critical reviews of our analytical approach and provoking thoughtful discussion of our conclusions. We also thank W. Perrin for a helpful review of this manuscript, as well as helpful reviews from anonymous reviewers.

\section{LITERATURE CITED}

Alvarez-Flores, CM (2002) Uncertainty in the management of activities affecting marine mammal populations. The tuna-dolphin conflict, a case study. PhD dissertation, University of Washington, Seattle, WA

Archer F, Gerrodette T, Dizon A, Abella K, Southern S (2001) Unobserved kill of nursing dolphin calves in a tuna purseseine fishery. Mar Mamm Sci 17:540-554

Archer F, Gerrodette T, Chivers S, Jackson A (2004) Annual estimates of the unobserved incidental kill of pantropical spotted dolphin (Stenella attenuata attenuata) calves in the tuna purse-seine fishery of the eastern tropical Pacific. Fish Bull 102:233-244

Ballance LT, Pitman RL, Spear LB, Fiedler PC (2002) Investigations into temporal patterns in distribution, abundance and habitat relationships within seabird communities of the eastern tropical Pacific. Southwest Fisheries Science Center, La Jolla, CA. Administrative Report LJ-02-17. (also available at: http://swfsc.noaa.gov/uploadedFiles/ Divisions/PRD/Programs/ETP_Cetacean_Assessment/LJ_ 02_17.pdf)

Bidigare RR, Ondrusek ME (1996) Spatial and temporal variability of phytoplankton pigment distributions in the central equatorial Pacific Ocean. Deep-Sea Res II 43:809-833

Chivers SJ, Scott MD (2002) Tagging and tracking of Stenella spp. during the 2001 Chase Encirclement Stress Studies Cruise. Southwest Fisheries Science Center, La Jolla, CA. Administrative Report LJ-02-33. (also available at: http:// swfsc.noaa.gov/uploadedFiles/Divisions/PRD/Programs/ ETP_Cetacean_Assessment/LJ_02_33.pdf)

Cooke JG (1995) The International Whaling Commission's Revised Management Procedure as an example of a new approach to fishery management. In: Blix AS, Walloe L, Ulltang $O$ (eds) Whales, seals, fish and man. Elsevier Science, Amsterdam, p 647-657

Cowan DF, Curry BE (2002) Histopathological assessment of dolphins necropsied onboard vessels in the eastern tropical Pacific tuna fishery. Southwest Fisheries Science Center, La Jolla, CA. Administrative Report LJ-02-24C. (also available at: http://swfsc.noaa.gov/uploadedFiles/Divisions/ PRD/Programs/ETP_Cetacean_Assessment/LJ_02_24C.pdf)

Dizon A, Allen A, Kellar N, Southern S (2002) Stress in spotted dolphins (Stenella attenuata) associated with purse-seine tuna fishing in the eastern tropical Pacific. Southwest Fisheries Science Center, La Jolla, CA. Administrative Report LJ-02-26. (also available at: http:// swfsc.noaa.gov/uploadedFiles/Divisions/PRD/Programs/ ETP_Cetacean_Assessment/LJ_02_26.pdf)

Eberhardt LL, Siniff DB (1977) Population dynamics and marine mammal management policies. J Fish Res Board Can 34:183-190

Edwards EF (2006) Duration of unassisted swimming activity for spotted dolphin (Stenella attenuata) calves: implications for mother-calf separation during tuna purse-seine sets. Fish Bull 104:125-135

Fiedler PC (2002) Environmental change in the eastern tropical Pacific Ocean: review of ENSO and decadal variability. Mar Ecol Prog Ser 244:265-283
Forcada J, Gazo M, Aguilar A, Gonzalvo J, Fernández-Contreras M (2004) Bottlenose dolphin abundance in the NW Mediterranean: addressing heterogeneity in distribution. Mar Ecol Prog Ser 275:275-287

Fowler CW (1981) Density dependence as related to life history strategy. Ecology 62:602-610

Fowler CW (1984) Density dependence in cetacean populations. In: Perrin WL, Brownell RL Jr, DeMaster DP (eds) Reproduction in whales, dolphins and porpoises, Spec Issue 6. International Whaling Commission, Cambridge, p 373-379

Gerrodette T, DeMaster DP (1990) Quantitative determination of optimum sustainable population level. Mar Mamm Sci 6:1-16

Gerrodette T, Forcada J (2005) Non-recovery of two spotted and spinner dolphin populations in the eastern tropical Pacific Ocean. Mar Ecol Prog Ser 291:1-21

Hall MA (1998) An ecological view of the tuna-dolphin problem: impacts and trade-offs. Rev Fish Biol Fish 8:1-34

Hinke JT, Kaplan IC, Aydin K, Watters GM, Olson RJ, Kitchell JF (2004) Visualizing the food-web effects of fishing for tunas in the Pacific Ocean. Ecology and Society 9:10 (also available at www.ecologyandsociety.org/vol9/iss1/art10)

Hoyle SD, Maunder MN (2004) A Bayesian integrated population dynamics model to analyze data for protected species. Anim Biodivers Conserv 27(1):247-266

IATTC (2002a) Annual report, 2000. Inter-American Tropical Tuna Commission, La Jolla, CA

IATTC (2002b) Annual report, 2001. Inter-American Tropical Tuna Commission, La Jolla, CA

IATTC (2004) Annual report, 2002. Inter-American Tropical Tuna Commission, La Jolla, CA

Joseph J, Greenough JW (1979) International management of tuna, porpoise, and billfish. University of Washington Press, Seattle

Kass RE, Raftery AE (1995) Bayes factors. J Am Stat Assoc 90:773-795

Landry MR, Kirshtein J, Constantinou J (1996) Abundances and distributions of picoplankton populations in the central equatorial Pacific from $12^{\circ} \mathrm{N}$ to $12^{\circ} \mathrm{S}, 140^{\circ} \mathrm{W}$. Deep-Sea Res II 43:871-890

Lennert-Cody CE, Buckland ST, Marques FFC (2001) Trends in dolphin abundance estimated from fisheries data: a cautionary note. J Cet Res Manag 3:305-319

Marques FFC, Buckland ST (2003) Incorporating covariates into standard line transect analyses. Biometrics 59:924-935

McPhaden MJ, Zhang D (2002) Slowdown of the meridional overturning circulation in the upper Pacific Ocean. Nature 415:603-608

McPhaden MJ, Zhang D (2004) Pacific Ocean circulation rebounds. Geophys Res Lett 31 L18301 doi:10.1029/2004 GL020727

Mesnick SL, Archer FI, Allen AC, Dizon AE (2002) Evasive behavior of eastern tropical Pacific dolphins relative to effort by the tuna purse-seine fishery. Southwest Fisheries Science Center, La Jolla, CA. Administrative Report LJ02-30. (also available at: http://swfsc.noaa.gov/uploadedFiles/Divisions/PRD/Programs/ETP_Cetacean_Assessment/ LJ_02_30.pdf)

Noren SR, Edwards EF (2007) Physiological and behavioral development in delphinid calves: implications for calf separation and mortality due to tuna purse-seine sets. Mar Mamm Sci 23:15-29

Pabst DA, McLellan WA, Meagher EM, Westgate AJ (2002) Measuring temperatures and heat flux from dolphins in the eastern tropical Pacific: Is thermal stress associated with chase and capture in the ETP-tuna purse seine 
fishery? Southwest Fisheries Science Center, La Jolla, CA. Administrative Report LJ-02-34C. (also available at: http:// swfsc.noaa.gov/uploadedFiles/Divisions/PRD/Programs/ ETP_Cetacean_Assessment/LJ_02_34C.pdf)

Pella JJ, Tomlinson PK (1969) A generalized stock production model. Inter-Am Trop Tuna Comm Bull 13:421-496

Perrin WF (1968) The porpoise and the tuna. Sea Frontiers 14(3):166-174

Perrin WF (1969) Using porpoise to catch tuna. World Fishing 18:42-45

Pitman RL, Ballance LT, Fiedler PC (2002) Temporal patterns in distribution and habitat associations of prey fishes and squids. Southwest Fisheries Science Center, La Jolla, CA. Administrative Report LJ-02-19. (also available at: http:// swfsc.noaa.gov/uploadedFiles/Divisions/PRD/Programs/ ETP_Cetacean_Assessment/LJ_02_19.pdf)

Press WH, Flannery BP, Teukolsky SA, Vetterling WT (1986) Numerical recipes. Cambridge University Press, New York

Reilly SB, Barlow J (1986) Rates of increase in dolphin population size. Fish Bull 84:527-533

Reilly SB, Donahue MA, Gerrodette T, Forney K and 8 others (2005) Report of the scientific research program under the International Dolphin Conservation Program Act. NOAA Tech Memo NMFS-SWFSC-372. (also available at: http://swfsc.noaa.gov/publications/TM/SWFSC/NOAATM-NMFS-SWFSC-372.PDF)

Rubin DB (1988) Using the SIR algorithm to simulate posterior distributions. In: Bernardo JM, DeGroot MH, Lindley DV, Smith AFM (eds) Bayesian statistics 3. Oxford University Press, Oxford, p 395-402

Santurtún Oliveros E, Galindo Maldonado F (2002) Coping behaviors of spotted dolphins during fishing sets. Southwest Fisheries Science Center, La Jolla, CA. Administrative Report LJ-02-36C. (also available at: http:// swfsc.noaa.gov/uploadedFiles/Divisions/PRD/Programs/ ETP_Cetacean_Assessment/LJ_02_36C.pdf)

Savage LJ (1962) The foundations of statistical inference. John Wiley \& Sons, New York

Smith TD (1983) Changes in size of three dolphin (Stenella spp.) populations in the eastern tropical Pacific. Fish Bull 81:1-13

Editorial responsibility: Otto Kinne (Editor-in-Chief), Oldendorf/Luhe, Germany
Southern S, Allen A, Kellar N (2002) Molecular signature of physiological stress in dolphins based on protein expression profiling of skin. Southwest Fisheries Science Center, La Jolla, CA. Administrative Report LJ-02-27. (also available at: http://swfsc.noaa.gov/uploadedFiles/Divisions/ PRD/Programs/ETP_Cetacean_Assessment/LJ_02_27.pdf)

St. Aubin DJ (2002) Hematological and serum chemical constituents in pantropical spotted dolphins (Stenella attenuata) following chase and encirclement. Southwest Fisheries Science Center, La Jolla, CA. Administrative Report LJ-02-37C. (also available at: http://swfsc.noaa.gov/ uploadedFiles/Divisions/PRD/Programs/ETP_Cetacean_ Assessment/LJ_02_37C.pdf)

Taylor BL, DeMaster DP (1993) Implications of non-linear density dependence. Mar Mamm Sci 9:360-371

Wade PR (1993) Estimation of historical population size of the eastern spinner dolphin (Stenella longirostris orientalis). Fish Bull 91:775-787

Wade PR (1994) Abundance and population dynamics of two eastern Pacific dolphins, Stenella attenuata and Stenella longirostris orientalis. PhD dissertation, Scripps Institution of Oceanography, University of California, San Diego, CA

Wade PR (1995) Revised estimates of incidental kill of dolphins (Delphinidae) by the purse-seine tuna fishery in the eastern tropical Pacific, 1959-1972. Fish Bull 93:345-354

Wade PR (1998) Calculating limits to the allowable humancaused mortality of cetaceans and pinnipeds. Mar Mamm Sci 14:1-37

Wade PR (1999) A comparison of statistical methods for fitting population models to data. In: Garner GW, Amstrup SC, Laake JL, Manly BFJ, McDonald LL, Robertson DG (eds) Marine mammal survey and assessment methods. A A Balkema, Rotterdam, p 249-270

Watters GM, Olson RJ, Francis RC, Fiedler PC and 7 others (2003) Physical forcing and the dynamics of the pelagic ecosystem in the eastern Tropical Pacific: simulations with ENSO-scale and global-warming climate drivers. Can J Fish Aquat Sci 60:1161-1175

Weihs D (2004) The hydrodynamics of dolphin drafting. J Biol 3:Article 8 (also available at http://jbiol.com/content/ pdf/jbiol2.pdf)

Submitted: July 4, 2006; Accepted: May 30, 2007

Proofs received from author(s): June 26, 2007 